\title{
APRESENTAÇÃO
}

\section{Fronteiras intermidiáticas do cinema}

Em novembro de 2015, o Cinemídia - Grupo de Estudos sobre História e Teoria das Mídias Audiovisuais do Programa de Pós-Graduação em Imagem e Som da Universidade Federal de São Carlos (UFSCar), que existe desde 2013 e é liderado por nós, autores que agora apresentamos este dossiê - realizou o I Encontro Internacional Cinemídia - Intermidialidades. O objetivo das conferências e comunicações foi estimular o debate e a investigação sobre modos de interação entre mídias e a ativação de suas zonas fronteiriças. No mesmo ano, alguns dos pesquisadores do Cinemídia nos engajamos no Projeto IntermIdia - towards an intermedial history of Brazilian Cinema: exploring intermediality as a historiographic method (para uma história intermidiática do cinema brasileiro: explorando a intermidialidade como um método historiográfico), um projeto colaborativo reunindo pesquisadores do Departamento de Filme, Teatro e Televisão da Universidade de Reading, Reino Unido (financiado por AHRC - Arts and Humanities Research Council) e pesquisadores da UFSCar (com financiamento da FAPESP) ${ }^{1}$ entre 2015 e 2018. O projeto centra-se na natureza do cinema como uma mistura de artes e mídias, a fim de produzir uma história intermidiática do cinema brasileiro. As pesquisas exploram a intermidialidade como um método historiográfico aplicável ao cinema como um todo. Com este objetivo, o projeto reúne pesquisadores da Universidade de Reading (UoR) e da UFSCar, que combinam conhecimentos em intermidialidade, cinema brasileiro, história do cinema, teoria do cinema, cinema 
e música, cinema e teatro, cinema e artes visuais e cinema e cultura popular. A profa. Lúcia Nagib, da UoR, é a coordenadora geral do projeto, e a profa. Luciana Corrêa de Araújo, da UFSCar, lidera a parte brasileira da pesquisa².

Este dossiê reúne algumas das conferências apresentadas no I Cinemídia³, acrescidas de um artigo da profa. Lúcia Nagib sobre os aspectos intermidiáticos de filmes brasileiros que usam o realismo como modo de produção. O I Cinemídia procurou avançar as indagações sobre o uso da intermidialidade como instrumento de pesquisa no campo do cinema, com o objetivo de minimizar o peso das grandes universalizações teóricas e discutir as possibilidades de uso da intermidialidade como uma metodologia de pesquisa.

Grande parte dos fenômenos tratados hoje sob o rótulo da intermidialidade não é propriamente nova. O que existe é um reconhecimento cada vez maior da capacidade deste conceito em apresentar uma nova maneira de pensar sobre tais fenômenos. Em um artigo seminal por sua capacidade de organizar o problema, publicado em 2005, Irina Rajewsky afirmava que o uso do termo "intermidialidade" tinha se generalizado a partir dos anos 1990 em diferentes tipos de abordagens que procuravam dar conta de fenômenos que aconteciam "entre as mídias". No contexto acadêmico alemão o termo já era largamente utilizado e discutido, assim como na Universidade de Montreal.

Em seu artigo, Rajewsky chamava a atenção para o fato de que o termo "intermidialidade" não coincide com nenhuma teoria unificada, sendo, portanto, necessário que cada estudo defina claramente, antes de mais nada, qual a concepção particular de intermidialidade do autor (2012, p. 18). Entretanto, é possível, para autora, diferenciar as configurações intermidiáticas dos fenômenos intramidiáticos e dos fenômenos transmidiáticos.

Considerada como um conceito "guarda-chuva", a intermidialidade contém, para Rajewsky, três diferentes categorias para estes fenômenos: "transposição 
midiática", "combinação de mídias" e "referências intermidiáticas". Adaptações de uma mídia para outra, como livros para filmes ou peças de teatro, com transferência de enredos e personagens, seriam "transposições midiáticas". Produtos culturais compostos por pelo menos duas mídias diferentes, como óperas, performances e filmes, seriam "combinações de mídias". A terceira categoria, que parece adaptar-se bem à análise fílmica, é a das "referências intermidiáticas", onde há a ilusão de haver, na mídia, práticas específicas de outra, numa espécie de evocação de suas técnicas (RAJEWSKY, 2012, p. 25).

Ágnes Pethő tem avançado a reflexão da intermidialidade para o cinema. Em seu livro Cinema and intermediality (2011), a pesquisadora propõe que os fenômenos intermidiáticos no cinema possuem caráter necessariamente autorreflexivo e fazem colidir, ao mesmo tempo, a imersão na obra e a quebra do fluxo narrativo - e isso pode acontecer não apenas nos casos de estilização quase antidiegética, mas também dentro de narrativas realistas. 0 momento de intermidialidade ocorre portanto quando o filme aponta ao mesmo tempo para o "mundo real" e para "sua própria midialidade". Pethő localiza esta lógica nos momentos mais ambíguos de certos filmes, nos quais uma mídia aparece como se fosse outra.

Assim como Rajewsky, Pethő também rompe com a apressada analogia que se faz entre intermidialidade e intertextualidade, usando o argumento de que nos fenômenos fílmicos intermidiáticos há um envolvimento sensório e corporal do espectador com o filme. Para ela, "enquanto a 'leitura' de relações intertextuais engaja nossas capacidades intelectuais, a 'leitura' de relações intermidiáticas requer, mais do que tudo, um espectador corporificado que entra 'em contato' com o mundo do filme [experimentando] diferentes níveis de consciência e percepção" (PETHŐ, 2011, p. 4)4.

Pethő discute esta questão no momento em que, na introdução do referido livro - Cinema and intermediality - apresenta o segundo capítulo, intitulado "Reading the intermedial: abysmal midiality and trans-figuration in the cinema". No texto original: "This chapter also breaks with the tradition of thinking of intermediality in analogy with intertextuality, and attempts a phenomenological (re)definition intermediality, based on the assumption that while 'reading' intertextual relations engages our intellectual capacities, 'reading' intermedial relations requires, more than anything else, an embodied spectator, who gets 'in touch' with the world of the film. Intermediality in film is grounded in the (inter)sensuality of cinema itself, in the experience of the viewer being aroused simultaneously on different levels of consciousness and perception". 
Por sua vez, Lúcia Nagib avança o pensamento sobre a intermidialidade investigando o momento do encontro entre filme e a realidade fenomênica do momento de filmagem, que é captado como componente político. Em artigo de 2014, Nagib discute a intermidialidade a partir do pensamento de André Bazin e sua noção de "cinema impuro", entendendo a intermidialidade como um problema, ou como um conjunto de procedimentos metafóricos que procuram sanar uma crise na criação artística e que indicam no filme um momento político (NAGIB, 2014, p. 22).

Já em seu artigo escrito especificamente para este dossiê e cujo título é "Passages: travelling in and out of film through Brazilian geography", Lúcia Nagib aborda a relação entre cinema e real por meio de um estudo de caso sobre filmes nos quais esta conexão aparece como uma "passagem", um momento privilegiado e fugaz em que filme e vida se misturam numa centelha política. Seus exemplos são escolhidos na cinematografia de diretores que despontaram na chamada Retomada do Cinema Brasileiro, ocorrida nos anos 1990, especificamente em produções pernambucanas e paulistas realizadas entre 1995 e 2016.

Cabe ressaltar que diversos estudos e pesquisadores sobre intermidialidade vêm do campo das Letras e da Literatura. Mais recentemente é que estas pesquisas estão ganhando corpo no campo do cinema, conforme podemos notar no artigo de Thaïs Flores Nogueira Diniz, "Intermidialidade: perspectivas no cinema". Nele, a pesquisadora descreve sua jornada pessoal no estudo das adaptações, a criação do grupo de pesquisa Intermídia, na UFMG, e a publicação de traduções de textos seminais sobre o assunto na série Intermidialidade e estudos interartes: desafios da arte contemporânea. Diniz comenta algumas abordagens mais conhecidas sobre a intermidialidade, como os escritos de Claus Clüver, Irina Rajewsky e Lars Elleström, bem como teóricos das adaptações literárias como Roman Jakobson, Linda Hutcheon, Dudley Andrew, Robert Stam e McFarlane. Em seguida, comenta exemplos de intermidialidade no cinema.

Por sua vez, o artigo de Carolin Overhoff Ferreira, intitulado "Transnacionalidade e intermidialidade em perspectiva pós-colonial: reflexões 
sobre coproduções contemporâneas de língua portuguesa", investiga esses conceitos apresentados já desde o título do seu texto, relacionando daí por diante um vasto panorama de observações e considerações sobre como a Arte foi sendo envolvida, no transcorrer do tempo, em prefixos tais como "trans", "inter" e "pós" em razão de interesses diversos implicados também em relações de poder. Colonialismo e neocolonialismo despontam então como eixos de seu estudo, que se volta de forma mais ampla à produção ou coproduções de filmes lusófonos, contudo chegando mais especialmente a uma análise do filme Tabu (2012), obra-prima de Miguel Gomes.

Outro autor que também esteve no I Cinemídia, Marcelo Prioste apresenta, em seu artigo "O cinema documentário na era da imagem técnica pós-fotográfica", uma reflexão na qual a questão da materialidade audiovisual - ou se preferirmos, de uma arqueologia das mídias - ganha especial relevo a partir das relações que o autor estabelece com técnicas de produção audiovisual não só concernentes às fotografias analógica e digital, mas também a toda uma circulação audiovisual própria de momentos diversos da história do documentário; estabelecendo interconexões. Nas análises de Prioste, encontraremos relações com filmes de diretores como Peter Watkins (Culloden, 1964; The war game, 1965) e sua aproximação a uma retórica da reportagem televisiva; Santiago Alvarez, explorando em noticieros do ICAIC a técnica do table top sobre fotografias, por exemplo, no curta L.B.J. (1968) sobre o presidente estadunidense Lyndon Baines Johnson. E a reflexão chega a realizadores dos anos 2000, como Jonathan Caouette (Tarnation, 2003), cuja linguagem é "referenciada na televisão, nos videoclipes e nos filmes $B$, que foram alinhavados numa intensa e provocativa estrutura narrativa" em uma produção de mínimos gastos que, valendo-se do iMovie, narra a história do próprio diretor, alcançando repercussão exponencial. Já no filme de Gabriel Mascaro (As aventuras de Paulo Bruscky, 2010), a vida e a obra do artista pernambucano são articuladas a partir do Second Life e, de forma assemelhada, os games e machinimas também estão no cerne das considerações apresentadas por Prioste sobre o filme dirigido por Alex Chan 
(The French democracy, 2005), o curta de Nick Gillin (Stigler, 2013) e a videoinstalação de Harun Farocki (Parallel, 2012-14).

Já a abordagem de Laura Cánepa em seu artigo "Mashups de horror, western e melodrama na série de televisão The Walking Dead", além de jogos eletrônicos, envolve mídias tais como cinema, literatura, publicidade, HQs, sendo que a própria expressão "mashup" (mistura) é proveniente da música eletrônica. Embora o objeto de sua discussão seja a série televisiva em questão, de fato, seu foco de investigação está voltado à compreensão de fenômenos de popularidade, aos porquês dos grandes índices de audiência alcançados por narrativas seriadas e complexas que, não por acaso, também envolvem gêneros tão afeitos à cultura popular quanto os que são mencionados em seu título (horror, western, melodrama) em uma circulação de referências entre mídias diversas que se retroalimentam ou operam por remediações. ${ }^{5}$ Tal característica tão forte em nossa época, a saber, a "remixagem", como propõe Cánepa com base em autores discutidos em seu texto, está em relação direta com a indústria cultural, no caso em questão reutilizando reiteradamente a figura do zumbi como forma de capitalizar nosso medo diante da possibilidade de um "mundo sem nós", seres humanos. Como estratégia industrial, também poderíamos pensar a intermidialidade neste caso na chave de práticas culturais reiteradas em contextos diversos, em que muitas vezes prevalece justamente a referência a determinados gêneros capazes de atrair tantos espectadores por vezes para ideais bastante conservadores.

Os artigos de Maurício de Bragança, Rodrigo Carreiro e Eduardo Vicente dedicam-se a explorar fenômenos intermidiáticos impulsionados, em boa medida, por "sonoridades". Bragança, a partir da presença determinante (1999), entretanto, parece oportuna a aproximação entre ambos os termos. Resumindo a noção de remediação e aplicando-a a um estudo sobre a intermidialidade entre cinema e pintura, Walter Moser (2006, p. 56) afirma: "Tomando como modelo a não-redução da riqueza semântica do termo utilizado por Bolter e Grusin, captarei nesse verbo um conjunto amplo de operações possíveis: retomar, reproduzir, re-(a)presentar, reutilizar, reciclar, revisitar, transferir, transmitir, transcodificar, transpor, etc." 
do bolero nos melodramas mexicanos dos anos 1940 e 1950 centrados no universo do cabaré - um espaço que é em si intermidiático e no qual a "figura da rumbeira é personagem central" - empreende uma reflexão que logo de início demonstra a impossibilidade de compreendermos o cinema como uma mídia pura, autônoma. No seu texto, intitulado "Cinema e intermidialidade na América Latina: o que a cabaretera tem a nos dizer sobre esse processo", o autor, que também estende sua reflexão ao cinema brasileiro desta mesma época ao elencar as inúmeras hibridizações que pontuam várias cenas dos filmes musicais cabareteros (com o rádio, o vaudeville e o teatro popular), defende que a cultura intermidiática possui um papel primordial não apenas na produção de sentidos, mas também na compreensão das "matrizes culturais" (MARTÍNBARBERO, 2001) que formataram os cinemas nacionais da América Latina nas primeiras décadas do cinema sonoro. Não obstante, como o texto conclui, tais aspectos ainda reverberam, de acordo com suas palavras, na "produção de sentidos proporcionada pela cultura das mídias contemporaneamente".

Aliás, é sobre uma faceta da produção de sentidos no audiovisual contemporâneo que o texto de Carreiro, cujo título é "A hora dos amadores: notas sobre a estética da imperfeição no audiovisual contemporâneo", discorre. Sua preocupação repousa na "crescente tendência à valorização de erros técnicos", inclusive de sonoridades propositalmente com "pouca legibilidade e clareza, mixadas de modo rústico" em produções audiovisuais recentes e que resultam em novos regimes de visualidade (RANCIÈRE, 2005) e de efeitos do real (BARTHES, 1972). O autor procura demonstrar que estas características estilísticas, por ele chamadas de "estética da imperfeição", embora configurem uma forte tendência em vários produtos audiovisuais da atualidade, habitam o cinema há muitas décadas. No entanto, no atual contexto de cultura participativa e de convergência midiática (JENKINS, 2009), conformaram um certo "padrão de gosto" para o público consumidor, chegando a constituir um índice "positivo" de distinção e valor cultural (BOURDIEU, 2007). 
Como já apontado por Bragança, as primeiras décadas do cinema sonoro no Brasil e no mundo são fortemente marcadas pela confluência de estéticas intermidiáticas, sobretudo com o teatro popular e com o rádio. Por esse motivo é que o dossiê traz como coda o texto de Eduardo Vicente, que pluraliza o mosaico reflexivo desta edição ao não abordar especificamente o cinema, mas sim as experiências estéticas singulares do drama radiofônico paulista nos anos 1950 . Em "Rádio Novo: a crítica social e a experimentação estética no rádio ficcional brasileiro dos anos 1950", o autor discorre sobre produções singulares que se diferenciaram das radionovelas da época - especialmente das produzidas pela Rádio Nacional do Rio de Janeiro - e que tinham como realizadores autores com vivências essencialmente intermidiáticas: Osvaldo Molles (escritor), Dias Gomes (autor teatral), Túlio de Lemos (cantor lírico) e Oduvaldo Vianna (autor teatral, diretor, roteirista e produtor de filmes). Vicente analisa peças radiofônicas dramáticas como as da série "Ópera em 1040 Quilociclos" (que adaptava enredos de óperas célebres para o cotidiano social e político de São Paulo) e pontua que obra destes autores intermidiáticos foi marcante tanto como "renovação estética" quanto como fator de "politização" no universo da ficção radiofônica nacional. Trata-se de uma reflexão cuidadosa que, ao abordar o que Rajewsky entende como "referências intermidiáticas" (RAJEWSKY, 2012) muito pode colaborar com o universo das pesquisas sobre as interseções entre rádio e cinema.

Como entusiastas das fronteiras, passagens e entrelaçamentos intermidiais do cinema, acreditamos que os textos aqui reunidos possam interessar aos pesquisadores da área do audiovisual e facilitar um maior intercâmbio de ideias. Desejamos uma boa leitura!

Flávia Cesarino Costa

Suzana Reck Miranda

Samuel Paiva Universidade Federal de São Carlos novembro de 2018 


\section{Referências}

BARTHES, R. O rumor da língua. São Paulo: Martins Fontes, 1972.

BOLTER, J. D.; GRUSIN, R. Remediation: understanding new media. Cambridge: MIT Press, 1999.

BOURDIEU, P. A distinção: crítica social do julgamento. Porto Alegre: Zouk, 2007.

JENKINS, H. Cultura da convergência. 2. ed. São Paulo: Aleph, 2009.

MARTÍN-BARBERO, J. Dos meios às mediações: comunicação, cultura e hegemonia. Rio de Janeiro: Editora UFRJ, 2001.

MOSER, W. "As relações entre as artes: por uma arqueologia da intermidialidade". In: Aletria, jul-dez, 2006, p. 42-65.

NAGIB, L. Politics of impurity. In: NAGIB, L.; JERSLEV, A. (Eds). Impure cinema: intermedial and intercultural approaches to film. London/New York: I.B. Taurus, 2014. p. 21-39.

PETHÖ, A. Intermediality in film: a historiography of methodologies. In: Cinema and intermediality: the passion for the in-between. UK: Newcastle upon Tyne: Cambridge Scholars Publishing, 2011. p. 19-54.

Rancière, J. A partilha do sensível: estética e política. São Paulo: Editora 34, 2005.

Dissensus: on politics and aesthetics. Trad. Steven Corcoran. New York/ London: Continuum, 2010. 
Thinking between disciplines: an aesthetics of knowledge. Parrhesia, v. 1 , p. $1-12,2016$.

RAJEWSKY, I. "Intermidialidade, intertextualidade, 'remediação': uma perspectiva literária sobre a intermidialidade". In: DINIZ, Thaís F. N. (Org.). Intermidialidade e estudos interartes: desafios da arte contemporânea, Belo Horizonte, Editora UFMG, 2012. p. 15-45. 